\title{
The Specification of Hydrological Model Requirements for Bog Restoration
}

\author{
Oskars Java \\ Vidzeme University of Applied Sciences
}

\section{INTRODUCTION}

Within the scope of biodiversity and sustainable ecosystem development, the restoration of a bog's ecosystem is important because by reducing the drainage effect on the bog, the negative impact on adjacent intact or relatively intact raised bog and other wetland hydrological regimes is lowered. Degraded bogs are mires with a disturbed natural hydrological regime, or those partly exploited for peat extraction. However, the hydrological regime can be restored and peat formation is expected within 30 years. The restoration of a bog's hydrological regime can be accelerated by filling up the drainage ditches.

In the course of researching scientific literature, the author has found no evidence of a system dynamics model developed to simulate tree cutting intensity in degraded bogs after filling the drainage ditches for the purpose of speeding up the restoration of the hydrological regime. Thus, this approach is an innovative way of solving the problem.

Bog hydrological systems are complex systems with many components, thus an interdisciplinary approach must be applied which combines hydrology, biology, geography and meteorology with computer sciences. Specification requirement technique is a useful tool for determining the elements that shape a bog's hydrological system and interact with each other, thus providing the design for a simulation model.

\section{MATERIAL AND METHODS}

In the opinion of the author, the most suitable specification requirement tool to determine components forming the bog hydrological system is (OOAD), because it is applicable both in system dynamics and object modelling systems. Based on OOAD, it will be able to build system dynamics models in STELLA system dynamics and the GEOframe NewAGE modelling system, which is based on an object modelling system framework.

OOAD principles are fundamentally based on real world objects (Powell-Morse, 2017) - in this case, the elements forming a bog's hydrological system.

OOAD combines all behaviours, characteristics and states into one analysis process, rather than splitting them up into separate stages, as many other methodologies would do (Powell-Morse, 2017).

OOAD can be divided in two parts - Object-Oriented Analysis (OOA), and Object-Oriented Design (OOD). The products of OOA serve as models from which we may start an object-oriented design; the products of OOD can then be used as blueprints for completely implementing a system using object-oriented programming methods (Booch, 1998).

In the study of the boundaries of the bog hydrological model, theoretical methods such as case study and content analysis were mainly used - specifically evaluative, explorative and instrumental review methods.

\section{RESULTS}

This study helped to understand complex interrelationships that exist between different elements within a bog's hydrological system. The bog hydrological system boundaries were clarified, and the simulation model specification requirements were determined.

\section{DISCUSSION}

The next step is to develop simulation models in STELLA system dynamics and the GEOframe NewAGE modelling system and compare the performance.

These simulation models will be made to represent water movement in a bog's hydrological system from water input by means of precipitation to water output through interception, sublimation, evaporation, transpiration, lake outflow and overland flow.

The input data will be loaded manually from the QGIS Open Source Geographic Information System and Excel databases. It will be possible to generate output data in the form of frequency tables, graphical analysis, review tables, GIS raster files and others.

\section{CONCLUSION}

The determination of tree thinning intensity in degraded bogs using modelling is a new innovative approach which should allow the water level of ecosystems to be restored faster and more efficiently, thus increasing natural diversity, improving the quality of life of local people and promoting bog recreational ability.

\section{KEYWORDS}

Requirement specification, imitation modelling, bog restoration. 